\title{
Alonso Jerónimo de Salas Barbadillo, Corrección de vicios, eds. David González Ramírez y Manuel Piqueras Flores, Madrid, SIAL Ediciones, 2019 (Colección Prosa Barroca, 17), 323 pp. ISBN: 978-84-17 825-48-4
}

\section{Giovanna Fiordaliso}

https://orcid.org/0000-0003-2823-8910

Università della Tuscia

ITALIA

g.fiordaliso@unitus.it

[Hipogrifo, (issn: 2328-1308), 8.2, 2020, pp. 883-886]

Recibido: 28-09-2020 / Aceptado: 06-10-2020

DOI: http://dx.doi.org/10.13035/H.2020.08.02.54

En el amplio panorama de la prosa de ficción de principios del siglo XVII, muchos son los autores que contribuyen al desarrollo y a la consolidación del género según nuevos patrones: su interés reside, por un lado, en cumplir el gusto de un públicoconsumidor todavía más aficionado a una ficción que, abandonados los mundos inverosímiles de los caballeros andantes o de los amantes idealizados de la novela sentimental, propone aspectos de su propia realidad más cercana y realista. Por otro, concretizan el deseo de representar esa misma realidad con una mirada irónica, incluso satírica, para exponer los vicios de una sociedad que está cambiando, donde la corte tiene un papel esencial y que el escritor, consciente de vivir un momento histórico crítico, decide contar destacando todas sus contradicciones y paradojas.

En este contexto se puede apreciar la figura de Alonso Jerónimo de Salas Barbadillo (1581-1635), escritor curioso, ingenioso, innovador y muy activo en su época, al lado de los célebres nombres de Cervantes, Lope de Vega, Góngora, Quevedo, con los que entabló relaciones y amistad. 
Dentro de su amplia producción, fruto de la pluma de un auténtico polígrafo, resulta un caso muy peculiar su cuarto libro, Corrección de vicios, obra juvenil publicada en Madrid en 1615, en la imprenta de Juan de la Cuesta, después del poema épico La patrona de Madrid restituida, impreso en 1609, de La hija de Celestina, de 1612 - con un nueva edición en 1614 con cambios y con el título de La ingeniosa Elena- y de la primera parte de El caballero puntual, de 1614.

Se trata de una de las más tempranas colecciones de relatos a la italiana escritas en España y la primera de varias colecciones de novelas que saldrán de la pluma del autor: una colección de ocho novelas -cinco de ellas en prosa y tres en verso - con marco agrupador, como ilustran David González Ramírez y Manuel Piqueras Flores en la introducción que abre el volumen.

En ella, los dos estudiosos contextualizan la obra dentro del ámbito de las colecciones de novela corta en español a principio del siglo XVII, marcado -claro estápor la publicación de Las novelas ejemplares de Cervantes, pero en relación a otros textos y autores que contribuyeron de forma decisiva a la circulación y consolidación del género. Subrayan a la vez su carácter original y «la búsqueda de nuevas formulaciones narrativas» (p. 51) en la composición de la obra. Añaden que «el texto no se volvió a publicar en su época, ni tampoco en los siglos XVIII y XIX, y la única edición moderna con la que contamos corre a cargo de Emilio Cotarelo (1907), que la incluyó en el tomo primero de su colección de varias obras que exhumó de Salas Barbadillo» (p. 62). Su edición crítica va por eso a colmar un vacío dentro de la muy amplia producción del autor madrileño, hasta ahora solo en parte conocida y apreciada.

Fijándose en la estructura de la colección, los curadores nos recuerdan que «Corrección de vicios cuenta con una singular cornice, compuesta a partir de elementos autobiográficos» (p. 13).

El texto lleva un subtítulo, En que Boca de todas verdades toma las armas contra la malicia de los vicios y descubre los caminos que guían la virtud, que apunta hacia su contenido y que es a la vez una indicación de lectura: se refiere por supuesto a un componente moral para justificar el texto y su utilidad, y se relaciona con los elementos presentes en el paratexto.

Después de un prólogo de Francisco Lugo y Dávila, se halla la dedicatoria de Salas Barbadillo a doña Ana de Zuazo, camarera de la reina Margarita, cuya presencia excede los límites de la dedicatoria misma: la obra se configura efectivamente como la narración del viaje que el mismo Salas Barbadillo hizo lejos de la corte y que dirige a doña Ana, presente como destinataria explícita a lo largo del texto con cierta regularidad. Utilizando como marco narrativo la comunicación epistolar del autor hacia una mujer real, el protagonista cuenta su viaje y su estancia en Tudela, donde encuentra un loco, Boca de todas verdades, con el que entabla conversación. El viaje se enriquece pues con las narraciones de Boca de todas verdades al protagonista, narratario de las ocho novelas, leídas la mayoría de ellas y solo una contada de forma oral, donde el loco Boca de todas verdades, personaje atractivo con rasgos muy parecidos a los del licenciado Vidriera cervantino, disecciona algún 
vicio propio de la sociedad áurea en sus discursos satíricos que dedica a temas o tipo concretos.

Estos son los rasgos que caracterizan Corrección de vicios.

Gracias a la labor de David González Ramírez y de Manuel Piqueras Flores, cuyo trabajo nace al amparo del proyecto de investigación «La poesía hispano-portuguesa de los siglos XVI y XVII: contactos, confluencias, recepción», la publicación de las obras de Salas Barbadillo se enriquece con esta edición crítica, manifestación del interés que el autor está despertando en la actualidad. Un autor cuya pluma se revela como un audaz instrumento para representar la sociedad y la realidad del barroco en todas sus contradicciones y paradojas, espejo de los vicios de la naturaleza humana, descrita en sus aspectos de hipocresía, codicia y obsesiones, con una mirada satírica y burlesca.

A pesar de pertenecer a la fase juvenil de la producción del madrileño, Corrección de vicios es una relevante muestra de su quehacer narrativo, de su afán innovador y de su intención de contribuir a la literatura de entretenimiento de su época respetando el célebre docere y delectare típico de la prosa de ficción del tiempo, como subrayan los dos curadores presentando las obras de Salas según los principios de «renovación e innovación» (p. 15).

En las novelas seleccionadas para constituir la colección, el motivo amoroso se une a la ambientación urbana, la burla a la sátira social, aprovechando algunos temas y motivos consuetos en la época, presentes también en sus obras sucesivas (la vanidad y la hipocresía de la nobleza; las características de la vida cortesana; el escarnio, las estafas; la apariencia y el honor; la mentira y la falsedad; la identificación, ilusoria y vana, entre patrimonio económico y virtudes, entre otros).

\section{Como afirma López Martínez}

cabe suponer, como han hecho habitualmente los estudiosos y como es indudable en el caso de otros autores, que esta obra surgió por influencia primordial de las Novelas ejemplares de Cervantes, publicadas el año anterior en la misma imprenta y para las que, además, Salas Barbadillo escribió la aprobación del reino de Aragón. Sin embargo, a pesar de que efectivamente se publicó después de aparecida la obra cervantina, los datos circunstanciales y el propio texto indican que fue escrita por Salas antes de tener acceso él mismo a las Ejemplares, aspecto que plantea una serie de preguntas de mucho interés para la historia de la novela corta española en este periodo señaladísimo de su desarrollo?

Por esta razón, en opinión de González Ramírez y Piqueras Flores

la novedad que representa Corrección de vicios es que asumió, en paralelo con Cervantes, [...] la utilidad social que podía tener la novela; su modelo narrativo -que empieza con un marco moralizador en el que Boca de todas verdades denuncia los males de una sociedad que consideraba en decadencia, y sigue con las nove-

1. José Enrique López Martínez, «Corrección de vicios de Salas Barbadillo, y la primera etapa de la novela corta española», Lejana. Revista Crítica de Narrativa Breve, 7, 2014, pp. 1-16. 
las, que funcionan en la mayoría de los casos como correctivos a modo de escarmientos - es pionero por concebir la novela corta con una claro talante reformista (p. 60).

Profundizando en un canon que rompe las fronteras nacionales y que tiene sus patrones en los grandes autores áureos españoles y en la tradición novelística italiana, Corrección de vicios resulta ser expresión de la polifonía literaria que caracteriza la realidad española del siglo XVII, con sus contradicciones y paradojas, que Salas Barbadillo supo contar en sus páginas a lo largo de todas sus obras.

Incluida en la colección «Prosa Barroca» dirigida por Rafael Bonilla Cerezo, la edición consta, además de la introducción y de la propuesta del texto con notas al pie que no entorpecen la lectura sino que la completan en lo necesario, de una bibliografía final, tan correcta como completa, que supone un punto de referencia para el estudio de la biografía de Salas Barbadillo y de la totalidad de su producción literaria.

En definitiva, nos encontramos ante un eslabón más en la cultura española del siglo XVII, de los que pueden aprovechar tanto los especialistas de literatura del Siglo de Oro como todos los lectores, invitados de esta forma a no desviar la mirada de la obra de un escritor tan peculiar como Salas Barbadillo. 